\title{
Urinary incontinence: A vibration alert system for detecting pad overflow
}

\author{
Bosco Fernandes, Patrick Gaydecki ${ }^{1}$, Felicity Jowitt and Eleanor van den \\ Heuvel $^{2}$ \\ ${ }^{1}$ School of Electrical and Electronic Engineering, University of Manchester, \\ Manchester M13 9PL, United Kingdom \\ ${ }^{2}$ Brunel Institute for Bioengineering, Brunel University, Uxbridge, UB8 3PH, United \\ Kingdom
}

Email: bosco.fernandes@manchester.ac.uk

\begin{abstract}
A sensor and electronics system is described that monitors the leakage of urine from continence pads into surrounding underwear. Urinary incontinence is involuntary loss of urine and occurs when the bladder muscles contract without warning or sphincter muscle surrounding the urethra are too weak to prevent leakage. The system comprises a wetness sensor and electronics unit. The sensor is stitched into the underwear and detects overspills of urine from the pad. The electronics unit is attached to the underwear and responds by vibrating, signalling to the wearer that pad has failed. This system has application for individuals who use continence pads in the community but it could also be used in care homes.
\end{abstract}

\section{Introduction}

Urinary incontinence is common in the adult population, but there is a wide range of prevalence rates reported in the literature. Some studies report levels as low as $11.5 \%$ in women and $6.9 \%$ in men, aged over 65 living in the community [1] but another study reported 58\% urinary incontinence in healthy middle aged women [2]. The wide variation in reported prevalence is caused by methodological differences between studies [3] with many studies not using standardised validated questionnaires, different time periods over which participants had to report and different definitions of urinary incontinence. The international continence society changed their definition of urinary incontinence from "Urinary incontinence is the involuntary loss of urine that is a social or hygienic problem" [4] to "-any involuntary loss of urine" [5], in an attempt to facilitate comparative epidemiological studies. Although precise prevalence levels are difficult to specify, it is generally accepted that prevalence of incontinence increases with age [6] and that more women than men are affected by urinary incontinence [7]. Surgical, medicinal and physiotherapeutic treatments that are available help to alleviate incontinence but if these treatments are not tried or to adhered to, while waiting for treatments to be effective or when treatments fail, continence pads are often chosen as a management option [8]. The global market for adult continence pads in 2008 was $\$ 44$ billion and it is also known that significant numbers of women manage their continence needs with menstrual pads [9]. It is therefore clear that vast numbers of people are regularly using pads. Whilst pads are useful for maintaining "social continence" [10], there are a number of problems associated with pad use. Research on the effect of wearing continence pads has shown that the ability of the pad to hold urine was the most important feature in both daytime and night time pad use. However, many women were 
concerned that the pad would leak and lived in a constant state of tension [11]. The inspiration for the device described in this paper came from Cheryle Gartley, the founder and president of The Simon Foundation for Continence whose professional and personal experience had impressed on her the need for an early warning system for pad leaks.

The system here described forms part of a large programme of work that is geared towards tackling the problems associated with continence difficulties in older people. At its core is a specially designed undergarment that informs the wearer of failure of the continence pad. The new system will give an early warning of pad leakage that will allow the user to change pads before wetness spreads to outer clothing and furniture. This will reduce embarrassment and worry for the wearer and the burden of cleaning wetted clothes and furniture.

The complete work programme encompasses a wide variety of different disciplines. Seven UK academic organisations are working on the project, in fields such as gerontology, odour chemistry, design of public facilities in the built environment and the development of pad leakage detection systems, of which the authors are contributors.

Urination or micturition is the process of disposing of urine from the bladder to the outside of the body via the urethra. Its operation is managed by the higher brain centres under the voluntary control of the individual. The urinary system has two distinct phases of operation; storage and voiding. Urine is stored in the bladder and can be voided by conscious brain activity. The stimuli for the voiding phase originates from sensory fibres at the bladder whose firing rates trigger the decision making process. A partially full bladder produces a low sensor firing rate [12]. During this state, the urethra and sphincter muscle are contracted and the bladder is distended [13]. At high bladder volume, the firing rate increases, causing a conscious sensation which makes the individual have an urge to void. Ideally, the individual eventually consciously initiates voiding, causing the bladder to contract and the outlet sphincter to relax. Voiding continues until the bladder empties completely. The bladder then relaxes and the urethral sphincter contracts, allowing the bladder to be refilled [12].

A number of elements in the bladder control cycle can become less efficient and can lead to urinary incontinence. Continence problems can also be exacerbated or caused by limited mobility as travelling to a suitable facility and transferring on to the toilet are an essential part of the continence process. For the purposes of this development project, a means of managing the continence problem is important but the cause of urinary incontinence is not relevant. Anyone who uses a pad to manage their continence and is concerned about potential pad leaks could benefit from the alerting system described. Unlike most assistive technologies, this device does very little to directly improve function or safety; the benefits of using the device are mainly in increased confidence for the user which should, in turn, facilitate greater participation.

\section{Current methods for monitoring urinary incontinence}

Several researchers and organisations worldwide have devised methods that allow urinary incontinence to be monitored and controlled. Most of these are designed to be used in care homes and consist of sensors placed inside continence pads and feature wireless signal transmission to care workers. A selection of the current methods is described below.

The Simpad is a design that incorporates a reusable sensor into a standard continence pad and uses a wireless network and central computer to monitor the patients and alert carers in a home [14]. It also has facilities for recording continence events.

The Stay-Dri design is marketed as a continence management system that links signals from reusable continence pads to wireless computer systems [15]. This system continuously monitors and records continence data in care homes. It is also interactive and can be used to provide prompts for restorative bladder programs. The alerts from this system can be used with pagers.

A device called SenseUrine measures minute changes in body temperature around the bladder area. The information is designed to be used to determine the urine volume in the bladder and alert the wearer in advance of an incontinence event occurring. [16].

Researchers have experimented with temperature measurement techniques to determine the onset of incontinence events [17]. They embedded sensors into continence pads that relied on the sudden 
rise in pad temperature due to urine to trigger an alarm signal. Their results showed that although the system operated successfully, low urine volume triggering could only be guaranteed by careful sensor positioning. Furthermore, the system could become unreliable if the temperature difference between abdominal skin and centre of the pad was low. The same researchers also investigated the use of an impedance method to detect incontinence. Their method relied on the urine to provide a conductive pathway between two electrodes on the pad, thus triggering the sensing electronics. They found that the system was successful in detecting urinary leaks but was also sensitive to pus exuding from bedsores.

Other systems exist that measure the flow profile of micturition, such as the Pe-Que sensor pad [18]. This device is used in urodynamics laboratories to investigate disorders in bladder function. This system is intended for clinical diagnostic investigation and therefore does not incorporate any alert signalling into the design.

The systems described above are all non-invasive since they do not require insertion into the body to detect and provide information about incontinence events. In contrast, other work has concentrated on the development of implantable systems. For example, a patent has been filed for an insertable sensor array system to monitor urinary incontinence [19]. The array contains pressure, leak detection, neuromuscular fatigue and electromyogram sensors, with a wireless unit for recording data. This system is designed to be diagnostic. It is mounted on a catheter that is inserted into the urethra for a period of 24 hours to several days. At the time of writing this document, such systems have not been found to be in physical existence.

None of the systems described in this section performs the same function as the new device described in this paper. While many different systems have been developed for monitoring incontinence, none was available to monitor the performance of the continence pad until the system described in this paper was developed.

\section{System design}

The system developed by the authors is different from the ones described above in two areas. The first area concerns the pad and undergarment. Continence pads tend to leak as the urine flow rate from the body often exceeds the speed of absorbance into the pad, allowing urine to flow freely across the surface of the pad without being absorbed. Furthermore, urine is always deposited in the same small area of the pad and is required to wick away from this area in order to allow more urine to be absorbed. Poor fit and incorrect application of the pad are also factors that cause leakage. If overspill on to the underwear occurs the pad wearer is likely not to be able to detect this immediately, especially if he or she is seated. Since the pad is next to the skin, there is unlikely to be a discernible temperature change that could signal overspill. This creates a situation where urine can seep from the wetted underwear onto outer clothing and thence to the surface of the seat. This sensor monitors the undergarment covering the pad and is able to detect urine coming into contact with the underwear. It does not obtain information directly from the continence pad itself.

The second area concerns the alert method used. This device is designed to notify the wearer that the continence pad has failed and that appropriate action therefore needs to be taken. The device is designed to assist pad wearers by alerting them to pad leaks before urine spreads, creating a potentially embarrassing situation.

The significant difference about this system is that it alerts the wearer directly, rather than sending information to a carer. In this regard, it is a portable system that can be used by otherwise healthy individuals who suffer involuntary loss of urine whilst carrying out their daily tasks. Around $20 \%$ of patients suffering from neurogenic bladder associated with spinal injury use a continence pad as part of their management strategy [20]. These individuals would only be able to benefit from the current system if the vibration unit were placed where they have normal sensation. However the authors have also developed a system which alerts the wearer or their carer of pad leakage by short messaging service (SMS). This version of the system might be more useful for people with reduced sensation. 
The sensors are integrated into the design of the underwear by embroidering two parallel conductive pathways on the underside of the underwear, closest to the leg holes. These are the locations where spillage from the pad is most likely to occur. A plain piece of cotton cloth is stitched above this layer to eliminate the risk of the pathways making false contact due to material creasing. The ends of the pathways terminate in press studs, to which the signalling unit is attached.

The signalling unit consists of a single round printed circuit board on which is mounted a microcontroller, a vibration unit, a coin cell and associated drivers. The device is normally on and in deep sleep mode, consuming minimal power. It is awoken when urine from a pad spills over and bridges the gap between the conductive pathways. The pathways effectively act as a switch which turns on in the presence of urine. When awake, the software within the microcontroller begins to execute and energises the vibration unit in a particular sequence. Being attached to the underwear, the user feels the vibration and can respond to the warning. The current flowing in the conductive pathways during active mode is $10 \mu \mathrm{A}$ and the signalling unit can be configured to provide single or repeated warnings, as necessary. It then returns to deep sleep mode.
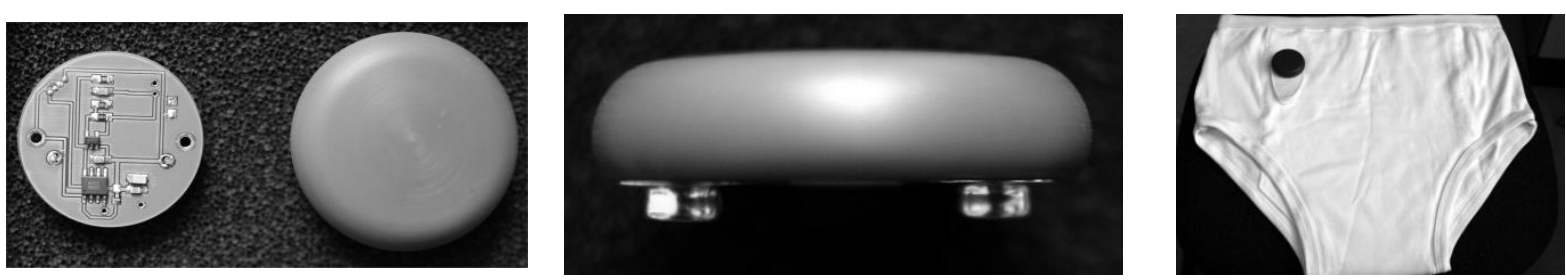

Figure 1. Urinary incontinence detection and signaling unit. The sensor is integrated into the underwear and the electronics unit is attached to it with press studs.

Figure 1 shows the PCB, enclosure and underwear. The PVC enclosure is custom designed to be smooth edged and of low profile. Standard press studs are used to attach the unit to the undergarment. The signalling unit is designed to be reusable.

\section{Experimentation and results}

Preliminary experiments to establish system design were conducted by fixing two conductors to a piece of cloth $10 \mathrm{~mm}$ apart and wetting the cloth with tap water, salty water and urine samples. At each test, the electrical resistance between the two electrodes was measured and recorded. Readings were taken after the liquid had absorbed into the material for one minute. The duration of time allowed the resistance value to settle to a constant, measurable value. The results are shown in Table 1.

Table 1. Results of resistance measurement tests on a piece of cloth with electrodes placed $10 \mathrm{~mm}$ apart.

\begin{tabular}{|l|c|}
\hline Test description & Resistance $(\boldsymbol{\Omega})$ \\
\hline $\mathrm{R}$ of dry cloth & $1 \mathrm{M}$ \\
\hline $\mathrm{R}$ of cloth soaked in tap water & $120 \mathrm{k}$ \\
\hline $\mathrm{R}$ of cloth soaked in saltwater (salt concentration of $\left.0.1 \mathrm{~mol}^{-1} \mathrm{I}^{-1}\right)$ & $80 \mathrm{k}$ \\
\hline $\mathrm{R}$ of cloth soaked in urine & $60 \mathrm{k}$ \\
\hline
\end{tabular}

It was found that when the cloth was dry, the resistance was in the megaohm region. With tap water, the resistance dropped to $120 \mathrm{k} \Omega$ and with salty water it was $80 \mathrm{k} \Omega$. Fresh urine had a resistance of $60 \mathrm{k} \Omega$ under the same conditions. These results provided the initial information that would allow the system to trigger with urine.

Following these tests, the first sensor pad system was designed and tested. It consisted of a folded piece of fabric on which two symmetrical patterns were embroidered with electrically conductive yarn. The pattern consisted of parallel lines terminating at a single connection area. Several pads were made 
with different numbers of lines. The patterns were separated from each other by a sheet of $1 \mathrm{~mm}$ thick absorbent fabric. The design is shown in Figure 2.
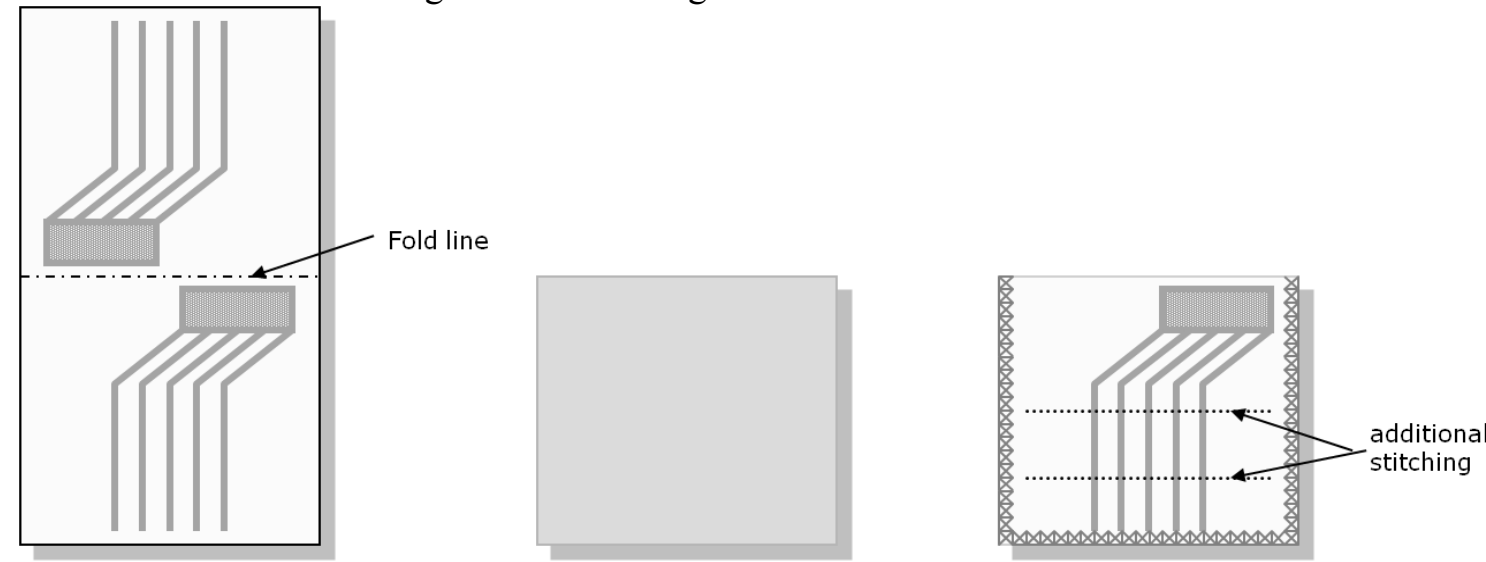

Figure 2. Initial sensor pad design showing the embroidered pattern, separator and assembled layout.

This system was used to examine its triggering capability in the presence of urine. An arrangement consisting of the sensor, amplifier, processor and $\mathrm{PC}$ was used to record the sensor response to being wetted by $10 \mathrm{ml}$ of salt water solution at a concentration of $0.3 \mathrm{~mol}^{-1} \mathrm{l}^{-1}$. It is shown in Figure 3.

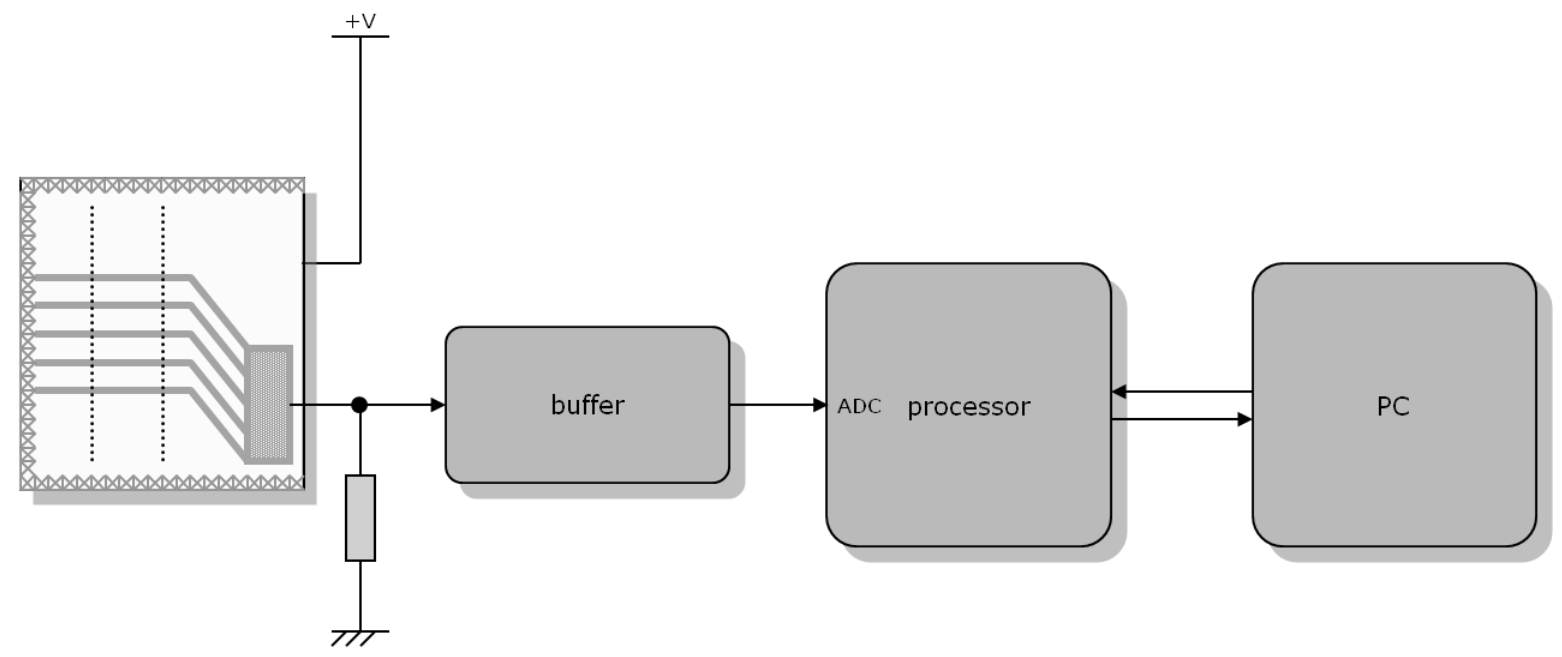

Figure 3. Experimental arrangement to test sensor response time.

The results obtained are shown in Figure 4. They indicate that the pads responded within 5 seconds of being wetted. It was also proven that changing the number of conductive lines did not have a significant effect on the final voltage output of the system.

A similar experiment to measure the conductivity of water with different concentrations of salt was also carried out. Salt solutions of $0.1 \mathrm{~mol} . \mathrm{l}^{-1}$ to $0.6 \mathrm{~mol} . \mathrm{l}^{-1}$ were prepared and tested using a similar data acquisition arrangement to the one shown in Figure 2. The results showed an exponential resistance drop from $80 \Omega$. to $20 \Omega$.with increases in salt concentration. In comparing these results with those from Table 1 above, it is noted that the resistance measurements taken across a wet piece e of fabric were different from those taken directly in the liquid, by 3 orders of magnitude. These results provided vital information to facilitate the design of a robust triggering circuit. 


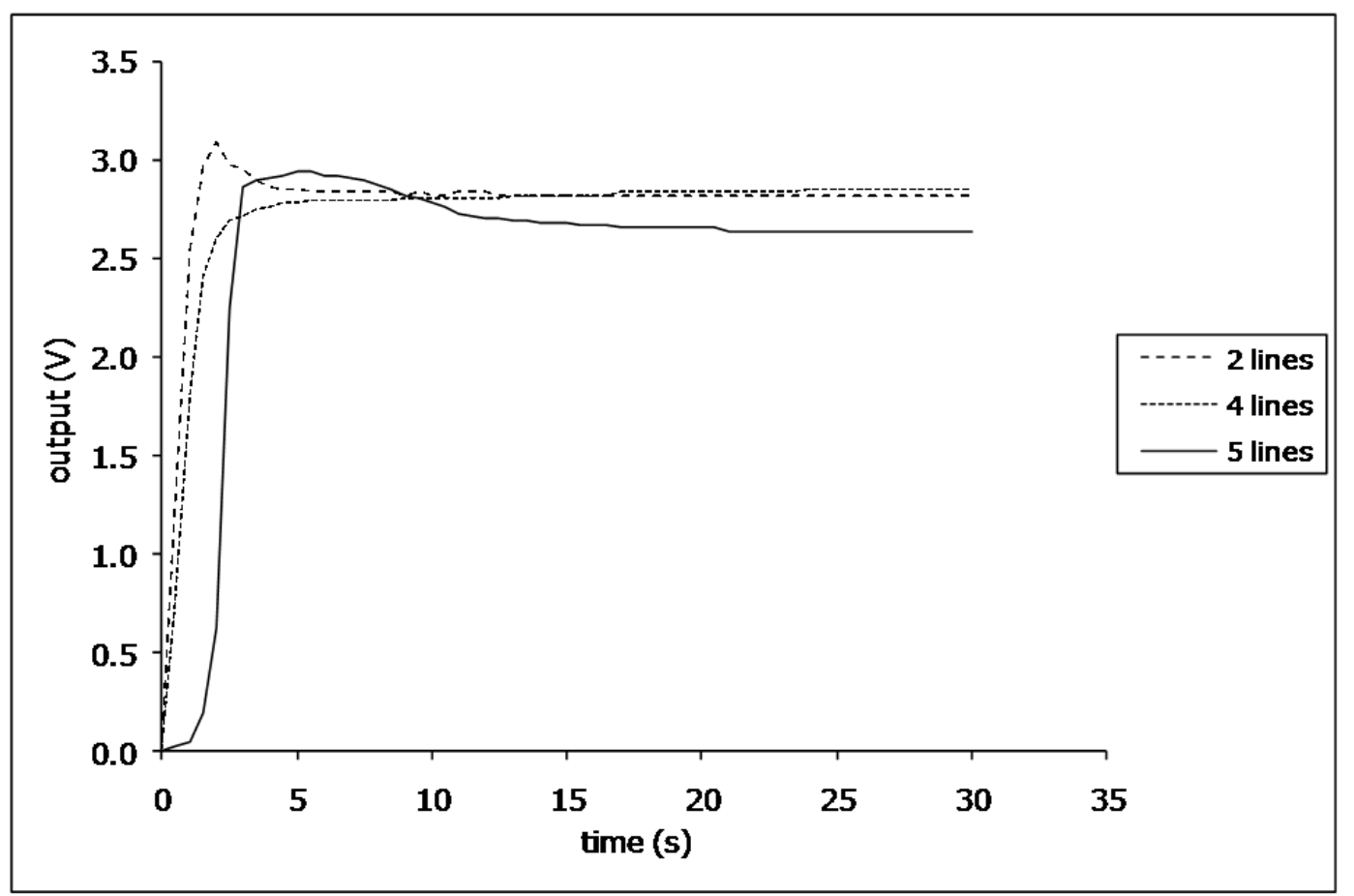

Figure 4. Results of an experiment to measure sensor response times to pad wetness.

Following the above experimentation, it was determined that the sensor would be fixed to the inside of an undergarment so that it could be used to detect urine overspill from a continence pad placed on it. The sensor would consist of four layers of sheeting, two of which would be used as separators to isolate the conductive layers from each other and the continence pad. The conductive layers would consist of patterns embroidered into the fabric using electrically conductive yarn. The initial layout was a comb pattern as shown in Figure 1and could pick up urine from any part of the underside of the continence pad. When, evaluated experimentally two problems were exposed. Firstly, it was found that the thickness of the sensor made the underwear uncomfortable to wear. Secondly, it was noted that urine overspill only occurred at the edges of the pad, rendering the majority of the embroidered patterned area useless.

As a result of the undergarment tests, an improved sensor, shown in Figure 5 was developed. In this version, the sensor thickness was reduced by sewing the conductive yarn as single tracks on the same layer of fabric. The two tracks were separated from each other by $10 \mathrm{~mm}$ and were positioned along the area corresponding to the sides of a continence pad, so that they would be ideally located to conduct upon urine overspill.

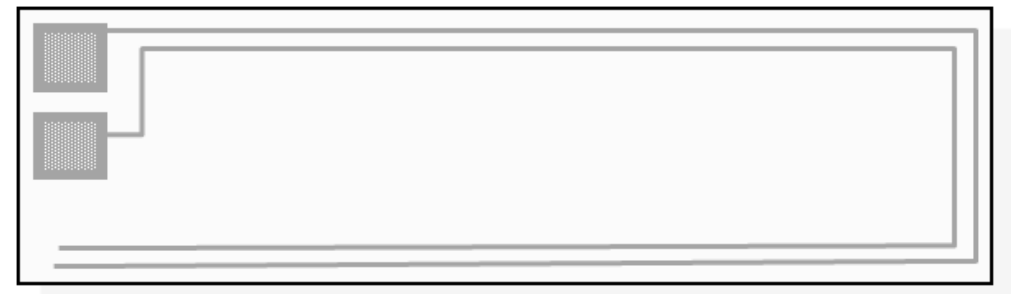

Figure 5. New sensor design.

This second design worked correctly in principle, but suffered from false triggering due to short circuits caused by fraying of the conductive yarn. The fraying had resulted from the use of multifilament conductive yarn in the sewing process causing it to break. A solution was found by 
using higher quality conductive yarn that remained intact after sewing. This allowed an efficient sensor design to be realised.

Another aspect of the system that required experimental evaluation was the design of the enclosure that was to house the signalling unit. The result of several focus group investigations made clear that the unit was to be small, light in weight, round and of low profile, so that it could be used discreetly. The final design obtained after a few iterations is shown in the photograph of Figure 1.

The information obtained from the experiments contributed to the design of a sensor that would be compatible with the signalling unit. At the time of writing, the signalling unit has been tested and awarded a CE mark. Pilot tests have also been carried out by volunteers and have yielded very promising results. Plans are now underway for the system to undergo more extensive clinical evaluation.

\section{Conclusion}

The system described above builds upon the already existing body of work that has been carried out to develop a robust method for the detection and warning of continence pad leakage during urinary incontinence events. The system provides assistance and reassurance for individuals who are managing a stigmatising condition. The integration of the sensor into specially designed underwear will allow the system to be used with many different types of incontinence pad. The underwear is designed to be used by a single individual to eliminate the risk of cross infection.

Although a functional system currently exists, there are several areas which need to be further investigated before it can become commercially acceptable. Possible false triggering due to sweat is currently being investigated and will provide information that will enable the sensing electronics and software to be reconfigured as necessary. The system will be optimised to be able to make an embedded decision about the type of trigger that was detected, before energizing the alert mechanism.

\section{Further work}

A fully working system opens up the possibility for a number of new sensing mechanisms to be incorporated into the already existing framework. A first step in this direction is to undertake a clinical evaluation of the current system; this is now being planned. The results will prove the system's repeatability and reliability so that it can be developed further.

\section{Acknowledgment}

The authors wish to thank the following organisations for their collaboration towards this work: Bristol Urology Institute, Helen Hamlyn centre, Royal College of Art, Sheffield Institute for Studies on Ageing, Sheffield Hallam University, University of Manchester School of materials, and the University of West of England.

\section{References}

[1] Thomas TM, Plymat KR, Blannin J, Meade TW. Prevalence of urinary incontinence. BMJ 1980; 281: 1243-5

[2] Burgio KL, Matthews KA, Engel BT. (1991) Prevalence, incidence and correlates of urinary incontinence in healthy, middle-aged women. J Urol. 1991 Nov;146(5):1255-9.

[3] Botlero, R., Urquhart, DM., Davis, SR., and Bell RJ. (2008) Prevalence and incidence of urinary incontinence in women: Review of the literature and investigation of methodological issues. International Journal of Urology 15, 230-234

[4] Abrams P, Blaivas JG, Stanton SL, Andersen JT (1988) The standardisation of terminology of lower urinary tract function. The International Continence Society Committee on Standardisation of Terminology. Scand J Urol Nephrol Suppl. 114:5-19.

[5] Abrams P, Cardozo, L, Fall, M Griffiths, D., Rosier, P., Ulmsten, U., Van Kerrebroek, P., Victor, A., Wein, A, The standardisation of terminology of lower urinary tract function: report 
from the Standardisation Sub-committee of the International Continence Society, Neurourol Urodyn 21 (2002), pp. 167-178

[6] Urinary incontinence in women (Clinical guideline 40). National Institute of Clinical and Healthcare Excellence, 2006, NCCWH, RCOG Press London, UK

[7] Brocklehurst JC. 1993. Urinary incontinence in the community. Analysis of a MORI poll. Br Med J 306:832-4.

[8] Desai, N.; Keane, T., Wagg, A; Wardle, J. 2008 Continence Care Provision of Continence Pads by the Continence Services in Great Britain: Fair All Round? Journal of Wound, Ostomy \& Continence Nursing:September/October 2008 - Volume 35 - Issue 5 - p 510-514

[9] McClish DK, Wyman JF, Sale PG, Camp J, Earle B. Use and costs of incontinence pads in female study volunteers.Continence Program for Women Research Group. J Wound Ostomy Contin Nurs 1999;26:207-8, 210-3.

[10] Lekan-Rutledge, D., Doughty, D., Moore, K. Wooldridge, L, (2003) Promoting Social Continence: Products and Devices In the Management Of Urinary Incontinence. Urologic Nursing; Dec2003, Vol. 23 Issue 6, p416-458, 14p

[11] Getliffe K, Fader M, Cottenden A, Jamieson K, Green N. Absorbent products for incontinence: 'treatment effect' and impact on quality of life. J Clin Nurs 2007; 16: 1936-45.

[12] Yoshimura, N., Chancellor, M.B., Neurophysiology of Lower Urinary Tract Function and Dysfunction, Rev Urol. 2003; 5(Suppl 8): S3-S10

[13] de Groat WC, Ryall RW., Reflexes to sacral parasympathetic neurones concerned with micturition in the cat, J Physiol. 1969 Jan;200(1):87-108.

[14] Simavita, (1996). SIMsystem, Retrived 07 September 2010, from http://www.fbh.net.au/Splash1.aspx.

[15] Technology for long term care, (2004). Stay-Dri, Retrived 07 September 2010 from http://www.techforltc.org/

[16] Yad Sarah (1976). Sensurine, Retrieved 07 September 2010, from http://www.yadsarah.org/

[17] Tamura, T.; Nakajima, K.; Matsushita, T.; Fujimoto, T.; Shimooki, S.; Nakano, T.; A monitoring and telemetering system of urinary incontinence for home health care, Proc. 15th Annual Intnl Conf. IEEE Eng Med \& Biol Soc, 1993 Pp:998 - 999.

[18] Pe-Que sensor pad, Retrived 07 September 2010 from http://www.digitimer.com/urodynamics/flow.htm

[19] Brown, W., Westcott, B., Si Luong, K., Sawyer, US Patent application no 20070225616, Wireless urinary incontinence monitoring system.

[20] Hansen RB., Biering-Sorensen F., and Kvist Kristensen J. (2010) Urinary incontinence in spinal cord injured individuals 10-45 years after injury. Spinal Cord 48 27-33 